\title{
PERBEDAAN FAKTOR RISIKO RESILIENSI PADA TINGKAT SISWA SMP, SMA DAN MAHASISWA POLITEKNIK (STUDI KASUS PADA SEKOLAH DI JAKARTA, JAWA TENGAH DAN JAWA TIMUR)
}

\section{Samsunuwiyati Marat ${ }^{1}$ Rita Markus Idulfilastri ${ }^{2}$ Fransisca Iriani R. Dewi ${ }^{3}$ Siti Bahiyah ${ }^{4}$}

${ }^{1}$ Fakultas Psikologi, Universitas Tarumanagara, Jakarta

Email: samsunuwiyatimarat34@gmail.com

${ }^{2}$ Fakultas Psikologi, Universitas Tarumanagara, Jakarta

Email: ritamarkus@fpsi.untar.ac.id

${ }^{3}$ Fakultas Psikologi, Universitas Tarumanagara, Jakarta

Email:fransiscar@fpsi.untar.ac.id

${ }^{4}$ Fakultas Psikologi, Universitas Tarumanagara, Jakarta

Email: siti.bahiyah06@gmail.com

\begin{abstract}
ABSTRAK
Penelitian mengenai resiliensi remaja secara indegenous belum banyak dilakukan. Penelitian mengenai faktor-faktor risiko di dalam resiliensi remaja Cina Benteng telah ditemukan adanya 7 (tujuh) faktor risiko yang dihadapi remaja yaitu (1) bencana alam (banjir), (2) pergaulan seks bebas, (3) penyalahgunaan narkoba, (4) bullying, (5) kemacetan lalu lintas, (6) pemalakan, (7) informasi negatif dari media sosial. Ke tujuh faktor risiko ini digunakan untuk menguji faktor risiko pada remaja dengan cakupan remaja yang lebih luas dan mempertahankan keragaman indigenous. Tujuan penelitian adalah menguji apakah ada perbedaan sikap pada remaja SMP, SMA dan Perguruan Tinggi sehingga remaja mampu bertahan atau keluar dari kesulitan hidupnya berdasarkan 7 faktor risiko resileiensi. Jumlah partisipan sebanyak 567 orang terdiri dari siswa SMP sebanyak 179 orang, siswa SMA sebanyak 221 orang dan mahasiswa duduk di semester 1 sebanyak 167 orang, sedangkan wilayah pengambilan data di Jakarta, Jawa Tengah-kota Purwokerto dan Jawa Timur-kota Bojonegoro. Pengolahan data menggunakan SPSS versi 22 dengan teknik statistik One-way ANOVA. Hasil pengujian adanya perbedaan (sig.< 0,05) pada faktor risiko bencana alam/banjir, perilaku seks bebas, narkoba, kemacetan lalu lintas dan informasi negatif dari media sosial. Artinya, siswa SMP, siswa SMA dan mahasiswa bersikap berbeda-beda terhadap faktor-faktor risiko tersebut. Sedangkan faktor risiko bullying tidak terbukti adanya perbedaan (sig.>0,05), dengan demikian ditanggapi dengan sikap sama antara siswa SMP, SMA dan Politeknik. Jika ditinjau dari tingkat pendidikan terbukti siswa SMA dan SMP bersikap sama (sig.>0,05) pada faktor risiko bencana alam dan kemacetan lalu lintas. Sedangkan, mahasiswa dan siswa mempunyai kesamaan sikap pada faktor risiko informasi negatif di media sosial. Terkait dengan budaya lokal terbukti bahwa remaja SMA di Jakarta, Purwokerto dan Bojonegoro berbeda sikap menyingkapi risiko yang dihadapinya terutama mengenai narkoba. Namun kesamaan sikap ketika dihadapi oleh situasi pemalakan dan mendapatkan informasi negatif dari sosial media. Remaja Jakarta mempunyai banyak sikap berbeda dengan remaja di Purwokerto dan Bojonegoro.
\end{abstract}

Kata Kunci: faktor risiko, resiliensi, remaja

\begin{abstract}
There is little research on indigenous adolescents' resilience. Research on risk factors in resilience of Benteng China adolescents has found 7 (seven) risk factors faced by adolescents, namely (1) natural disasters (floods), (2) promiscuity, (3) drug abuse, (4) bullying, (5) traffic congestion, (6) mugging, (7) negative information from social media. These seven risk factors are used to test risk factors broader range of adolescents while maintaining maintain indigenous diversity. The purpose of this study is to test whether there are differences in attitudes in adolescents of junior high, high school and tertiary institutions that allow adolescents to survive or solve their life issues based on the 7 risk factors for resilience. The number of participants were 567 people consisted of 179 junior high school students, 221 high school students and 167 students in semester 1 of tertiary education, while the data collection areas were in Jakarta, Central Java in Purwokerto and East Java in Bojonegoro. Data was processed using SPSS version 22 with One-way ANOVA statistical technique. The test results show differences (sig. <0.05) on risk factors for natural disasters / floods, free sex, drugs, traffic jams and negative information from social media. This means that middle school students, high school students and college students behave differently towards these risk factors. Meanwhile the risk factors for bullying have not shown significant differences (sig.> 0.05), causing similar responses among middle, high school and polytechnic students. When viewed from the level of education it is
\end{abstract}


proven that high school and junior high school students behave in the same way (sig.>0.05) on natural disaster risk factors and traffic congestion. Meanwhile, college students and students have the same attitude towards negative information on social media. Associated with local culture, it is evident that high school students in Jakarta, Purwokerto and Bojonegoro have different attitudes toward the risks they face, especially regarding drug abuse but similar attitudes when faced with mugging and exposure to negative information from social media. Adolescents in Jakarta show many different attitudes compared to adolescents in Purwokerto and Bojonegoro.

Keyword: risk factor, resilience, adolescents

\section{PENDAHULUAN}

Penelitian resiliensi, menurut Rutter (dalam Unger, 2013) menekankan pada berbagai hal: (a) pengembangan kontektual dan perjalanan sosial (social trajectories), (b) mengidentifikasi perubahan-perubahan kritis dan lingkungan materialnya yang mengarahkan perjalanan seseorang menjadi lebih baik dan sejahtera (well-being). Dengan demikian, konteks (context) dan sumber (resource) adalah titik balik untuk perjalanan resiliensi yang ingin dicapai. Kajian tersebut menurut Ungar (2012) resiliensi dengan pendekatan ekologi sosial. Pendekatan ekologi sosial, dikembangkan Brofenbrenner (1979), bahwa perkembangan individu dalam sistem sosial dipengaruhi (1) sistem ekologi seperti sistem mikro seperti keluarga, teman sebaya, lingkungan sekolah, (2) sistem meso dan exo, yaitu interaksi antara dukungan keluarga dan sekolah, keterkaitan dengan ketetanggaan, dan (3) sistem makro, yaitu institusi agama dan praktek-praktek budaya. Berdasarkan hal tersebut, penulis menggunakan budaya (culture) sebagai konteks dan sumber untuk melakukan kajian atas resiliensi remaja dalam kehidupan sehari-hari dalam menjalankan tugas perkembangannya.

Kondisi kehidupan yang dialami masyarakat serta pekerjaan yang tidak menentu menyebabkan masyarakat terus berada dalam situasi yang sulit. Stresor ini akan berubah menjadi krisis bila mereka tidak menggunakan kemampuan-kemampuan yang ada dalam diri mereka. Glicken (2006) berpendapat bahwa krisis dalam keluarga meliputi masalah keuangan, kesehatan, pengangguran, pernikahan, perilaku kasar dari caregiver, masalah sosial dan emosional anak, kehilangan tempat tinggal, dan sejumlah masalah lainnya yang dapat memengaruhi seluruh keluarga baik dari segi fisik maupun psikologisnya.

Masyarakat umumnya mengalami krisis dalam hal keuangan, pekerjaan, dan tempat tinggal (Ginting, 2009). Meskipun begitu, beberapa keluarga mampu bertahan serta beradaptasi dengan permasalahan yang muncul akibat dari perubahan tersebut (Dwi, 2010). Menurut Sherly (dikutip dalam Adi, 2006) sebagai contoh kehidupan masyarakat Cina Benteng memang keras agar bisa bertahan hidup. Masyarakat Cina Benteng mampu menyelesaikan masalahnya dan melihat masalah sebagai tantangan, menjadi lebih kuat serta percaya diri setelah menghadapi masa-masa yang sulit. Kemampuan untuk beradaptasi secara positif terhadap keadaan atau situasi yang sulit disebut dengan resiliensi. Resiliensi diartikan sebagai kemampuan seseorang untuk pulih atau menyesuaikan diri pada saat-saat sulit (King, 2008). Berbeda dengan Schoon (2006) faktor pelindung memiiliki peran dalam memodifikasi efek negatif dari kehidupan yang tidak menguntungkan dan membantu menguatkan resiliensi. Beberapa faktor pelindung yang penting meliputi perayaan keluarga seperti ulang tahun atau hari libur, daya tahan dan kesehatan keluarga, rutinitas dan waktu keluarga, serta tradisi keluarga (Matthews, 2003).

Sebaliknya, faktor risiko (risk factors) merupakan kebalikan dari protective factors yaitu situasi atau faktor yang meningkatkan kemungkinan munculnya hasil yang buruk (Ministry of Social Development, 2005). Beberapa kajian di atas menunjukkan adanya strategi keluarga untuk terus bertahan hidup meskipun individu mengalami krisis atau masalah. Strategi dan kemampuan yang dimiliki oleh keluarga, diduga juga memengaruhi anak-anaknya dalam hal ini remaja (protective 
factors). Krisis yang terjadi pada remaja, menurut penulis lebih disebabkan kondisi ekonomi orangtua yang berimbas pada kesulitan pendidikan dan pekerjaan. Sebagai tahap awal penulis tertarik melakukan kajian tentang resiliensi remaja-remaja berdasarkan tingkat pendidikan melalui pendekatan psikologi indigenous.

Sampai saat ini, penelitian yang khas Indonesia atau indigenous belum banyak dilakukan. Penelitian ini perlu dilakukan karena teori-teori yang berasal dari barat (Amerika dan negara Eropa lainnya) tidak selalu cocok atau dapat diterapkan untuk di Asia. Kajian psikologi indigenus yang dilakukan di Korea, India dan Jepang membuktikan hal ini (Kim, Yang, \& Wang, 2006). Sementara di Indonesia telah dilakukan beberapa penelitian untuk mendalami psikologi khas Jawa yang dilakukan oleh tim penelitian Universitas Gadjah Mada, mengenai diri (self), kepercayaan (trust), prestasi (achievement). Psikologi indigenous merepresentasikan transaksi paradigm ilmiah, dimana individu dipandang sebagai agen dari tindakannya dan agen kolektif melalui budaya mereka. lebih lanjut dikatakan oleh Kim bahwa dalam ilmu sosial, individu adalah sebagai pelaku (subyek) maupun obyek penyelidikan. Dalam psikologi, penelitian memerlukan perspektif dari pengalaman orang pertama (agency, kepercayaan/belief, makna dan intensi). Resiliensi sesuatu hal yang penting merupakan kemampuan manusia untuk menghadapi, mengatasi dan menjadi kuat bahkan merubah kemalangan hidup (Grotberg,, 1995). Menurut Grotberg,, resiliensi terjadi karena factor-faktor yang menjadi sumber terbentuknya resiliency yaitu I have, I am dan I can. I have merupakan sumber yang berasal dari luar diri individu (eksternal) yang dapat meningkatkan resiliensi, individu memerlukan dorongan eksternal untuk membentuk perasaan keselamatan dan perasaan aman yang merupakan dasar dari berkembangnya resiliensi. I am merupakan kekuatan yang berasal dari dalam diri sendiri yang terdiri dari perasaan, sikap, dan keyakinan pribadi. I can, yang merupakan kemampuan sosial dan interpersonal seseorang. Berdasarkan ketiga sumber resiliencsi tersebut maka seseorang dapat dikatakan memiliki dan ketiga sumber resiliensi tersebut berasal dari faktor eksternal dan internal individu.

Penelitian mengenai resiliensi remaja secara indegenous belum banyak dilakukan. Sebagai bagian konstribusi peneliti untuk menambah kajian tentang psikologi indigenous, telah dilakukan penelitian mengenai resiliensi remaja Cina Benteng di Tangerang (Dewi \& Marat, 2013). Penelitian mengenai faktor-faktor risiko di dalam resiliensi remaja Cina Benteng dan ditemukan 7 aspek yang dihadapi yaitu (1) bencana alam (banjir), (2) pergaulan seks bebas, (3) penyalahgunaan narkoba, (4) bullying, (5) kemacetan lalu lintas, (6) pemalakan, (7) informasi negatif dari media social. Ketujuh aspek tersebut kemudian digunakan oleh peneliti untuk menguji faktor risiko untuk remaja dengan cakupan remaja yang lebih luas dan mempertahankan keragaman indigenous. Jadi, tujuan penelitian ini untuk menguji apakah ada perbedaan pada remaja SMP, SMA dan Perguruan Tinggi terhadap 7 (tujuh) faktor risiko dihadapi sehingga remaja mampu bertahan atau keluar dari kesulitan hidupnya. Hipotesis penelitian adalah ada perbedaan rerata pada kelompok remaja SMP, SMA dan Perguruan Tinggi.

Dengan temuan penelitian ini diharapkan membantu dalam hal penanganan terhadap remaja-remaja yang mengalami kesulitan. Temuan yang diperoleh pada penelitian ini terkait dengan budaya local, oleh karena itu diharapkan penanganan remaja bermasalaah dapat dikaitkan dengan pendekatan budaya lokal. 


\title{
2. METODE
}

\section{Karakteristik partisipan}

Karekteristik partisipan adalah remaja yang masih bersekolah di SMP, SMA dan mahasiswa di semester 1. Pengambilan sampel remaja di sekolah dikaitkan dengan lokasi yang berhubungan dengan budaya lokal. Mengingat tidak ada definisi yang sama mengenai usia remaja maka diambil dari usia terendah sampai tertinggi sesuai definisi, yaitu 12 tahun sampai 21 tahun. Usia siswa SMP berkisar 13 tahun sampai 15 tahun, usia siswa SMA berkisar 16 tahun sampai 18 tahun dan mahasiswa Perguruan Tinggi di semester I, dengan usia 19 tahun sampai 21 tahun.

Jumlah partispan sebanyak 567 orang yang terdiri dari siswa SMP sebanyak 179 orang, siswa SMA sebanyak 221 orang dan mahasiswa sebanyak 167 orang. Jika diuraikan setiap provinsi sebagai berikut wilayah pengambilan data di Jakarta, Jawa Tengah di kota Purwokerto dan Jawa Timur di kota Bojonegoro. Jumlah siswa di Jakarta berasal dari siswa SMP Negeri 61 sebanyak 84 siswa, SMP Negeri 130 sebanyak 95 siswa; SMA Negeri 96 sebanyak 104 siswa. Jumlah siswa di Jawa Tengah berasal dari SMA Katolik sebanyak 84 siswa. Jumlah siswa di JawaTimur dari SMA Bojonegero sebanyak 33 siswa. Sedangkan mahasiswa berasal dari Politeknik Ketenagakerjaan Bekasi sebanyak 167 mahasiswa. Perlu diketahui bahwa mahasiswa Politeknik ini mahasiswa kedinasan yang berasal dari semua provinsi Indonesia.

\begin{abstract}
Alat ukur
Alat ukur yang digunakan adalah kuesioner risiliensi berdasarkan 7 faktor risiko dan telah diuji validitas konstruk menggunakan Confirmatory Factor Analysis (Dewi \& Marat, 2013), jumlah 70 butir valid dan menggunakan skala sikap pilihan 1 sampai dengan 5 (sangat kurang sampai dengan sangat setuju). Jumlah butir pada faktor-faktor risiko resiliensi sebagai berikut (1) faktor bencana alam /banjir terdiri dari 9 butir valid; Contoh butir: Dalam menghadapi bencana alam kami yakin ada tempat untuk berlindung. Ketika menghadapi situasi yang sulit atau tertekan, saya mencari penyelesaian. (2) faktor perilaku seks bebas terdiri dari 11 butir; Contoh butir: Saya sudah dibekali dengan pendidikan agama sehingga tidak takut dengan lingkungan pergaulan yang tidak baik. Nilai-nilai yang ditanamkan keluarga, mampu menghindari pergaulan seks bebas (3) faktor penyalah gunaan narkoba terdiri dari 15 butir valid; Contoh butir: Remaja memakai narkoba karena ikut-ikutan atau trend. Saya berkomitmen untuk tidak merusak masa depan saya dengan menggunakan narkoba (4) faktor bullying terdiri dari 9 butir valdi; Contoh butir: Seseorang yang mengalami bulliying, akan membuat dirinya menjadi lebih sabar. Jika seseorang merasa tidak salah, tidak takut untuk menghadapi perilaku bullying (5) faktor kemacetan di jalan terdiri 9 butir valid; Contoh butir: Saya selalu mencari informasi jalanan yang tidak macet ketika akan bepergian. Saya tidak merasa bosan dalam kemacetan di jalan, karena saya bermain gadget. (6) faktor pemalakan terdiri dari 8 butir valid; Contoh butir: Saya pasrah dan rela ketika harta (barang) kita diambil paksa orang lain. Karena saya dapat melindungi diri, maka tidak mengalami pemalakan (7) faktor informasi negatif dari media social terdiri dari 9 butir; Contoh butir: Saya selektif atas informasi yang masuk dari media sosial (medsos). Jika mendengar informasi media sosial, tidak mudah langsung mempercayainya.
\end{abstract}

\section{Olah data}

Olah data menggunakan SPSS versi 22 dengan teknik ANOVA untuk mengetahui perbedaan rerata yang signifikan antara kelompok. Langkah pertama dilakukan test of homogeneity of variances untuk menguji apakah kelompok mempunyai varians yang sama. Langkah kedua pengujian signifikansi terhadap 7 faktor risiko resiliensi. Langkah ketiga pengujian signifikansi terhadap kelompok SMP, SMA dan Perguruan Tinggi. Langkah ke empat pengujian signifikansi terhadap kelompok SMP, SMA pada wilayah berbeda. 


\section{HASIL DAN PEMBAHASAN}

Pengujian dengan test of homogeneity of variances untuk mengetahui asal sampel dari populasi yang sama. Jika berasal dari poulasi yang sama maka kelompok siswa SMP, SMA dan Perguruan Tinggi berasal dari populasi yang sama. Namun kenyataan memperlihatkan pada faktor risiko narkoba dan faktor risiko informasi negatif dari media social ternyata diperoleh variansi yang tidak sama (sig.<0,05). Oleh karena itu, dapat dikatakan bahwa kelompok SMP merupakan sampel dari populasi SMP, kelompok SMA merupakan sampel dari populasi SMA dan kelompok Politeknik merupakan sampel dari populasi Politeknik. Penjelasan dapat dilihat pada Tabel 1.

\section{Uji populasi}

Tabel 1. Test of Homogeneity of Variances

\begin{tabular}{cccc}
\hline Faktor Risiko & Statistik Levene & Sig. & Penjelasan \\
\hline Banjir/Bencana Alam & 0,490 & 0,613 & Variansi sama \\
\hline Perilaku Seks Bebas & 0,924 & 0,398 & Variansi sama \\
\hline Narkoba & 3,528 & 0,030 & Variansi tidak sama \\
\hline Bullying & 0,040 & 0,961 & Variansi sama \\
\hline Kemacetan lalu lintas & 1,136 & 0,322 & Variansi sama \\
\hline Pemalakan & 0,317 & 0,728 & Variansi sama \\
\hline Informasi Negatif & 7,022 & 0,001 & Variansi tidak sama \\
\hline
\end{tabular}

\section{Uji beda rerata faktor risiko resiliensi}

Berdasarkan uji beda rerata faktor risiko menggunakan ANOVA membuktikan adanya perbedaan yang signifikan (sig.<0,05) pada faktor risiko bencana alam/banjir, faktor risiko perilaku seks bebas, faktor risiko narkoba, faktor risiko kemacetan lalu lintas dan faktor risiko informasi negatif. Maksudnya, siswa SMP, siswa SMA dan mahasiswa Perguruan Tinggi memahami dengan sikap yang berbeda-beda. Sedangkan faktor risiko bullying tidak terbukti adanya perbedaan (sig>0,05), dengan demikian ditanggapi dengan sikap sama antara siswa SMP, SMA dan Politeknik. Penjelasan dapat dilihat pada Tabel 2.

Tabel 2. Pengujian beda rerata dengan ANOVA

\begin{tabular}{cccc}
\hline Faktor Risiko & F & Sig. & Penjelasan \\
\hline Bencana Alam/banjir & 6,738 & 0,01 & Terbukti berbeda \\
\hline Perilaku Seks Bebas & 72,998 & 0,00 & Tebukti berbeda \\
\hline Narkoba & 67,412 & 0,00 & Terbukti berbeda \\
\hline Bullying & 0,329 & 0,720 & Tidak terbukti berbeda \\
\hline Kemacetan lalu lintas & 9,733 & 0,000 & Terbukti berbeda \\
\hline Pemalakan & 11,786 & 0,000 & Terbukti berbeda \\
\hline Informasi Negatif & 3,652 & 0,027 & Terbukti berbeda \\
\hline
\end{tabular}

\section{Uji beda rerata faktor risiko resiliensi berdasarkan tingkat pendidikan}

Pengujian dilanjutkan dengan memperhatikan pada tingkat pendidikan. Ternyata pada faktor risiko bencana alam dan faktor risiko kemacetan lalu lintas ditanggapi dengan sikap sama antara siswa SMA dengan siswa SMP (sig.>0,05). Sedangkan faktor risiko informasi negatif ditanggapi dengan sikap sama antara mahasiswa Politeknik (sig.>0,05) dengan siswa SMP dan SMA. Faktor risiko bullying memang sudah diketahui tidak ada beda atau bersikap sama antara siswa SMP, SMA dan mahasiswa Politeknik (sig $>0,05)$. 
Tabel 3. Pengujian beda rerata pada Tingkat Pendidikan

\begin{tabular}{|c|c|c|c|}
\hline Faktor Risiko & Sekolah & SMA & SMP \\
\hline \multirow[t]{2}{*}{ Bencana Alam/Banjir } & Politeknik & 0,006 & 0,002 \\
\hline & SMA & & $\left.0,898^{*}\right)$ \\
\hline \multirow[t]{2}{*}{ Perilaku Seks Bebas } & Politeknik & 0,000 & 0,000 \\
\hline & SMA & & 0,000 \\
\hline \multirow[t]{2}{*}{ Narkoba } & Politeknik & 0,000 & 0,000 \\
\hline & SMA & & 0,000 \\
\hline \multirow[t]{2}{*}{ Bullying } & Politeknik & $\left.0,978^{*}\right)$ & $\left.0,723^{*}\right)$ \\
\hline & SMA & & $\left.0,810^{*}\right)$ \\
\hline \multirow[t]{2}{*}{ Kemacetan lalu lintas } & Politeknik & 0,000 & 0,001 \\
\hline & SMA & & $\left.0,922^{*}\right)$ \\
\hline \multirow[t]{2}{*}{ Pemalakan } & Politeknik & 0,093 & 0,000 \\
\hline & SMA & & 0,007 \\
\hline \multirow[t]{2}{*}{ Informasi Negatif } & Politeknik & $\left.0,812^{*}\right)$ & $\left.0,147^{*}\right)$ \\
\hline & SMA & & 0,023 \\
\hline
\end{tabular}

Pengujian menggunakan One-way ANOVA,Post Hoc Test, Multiple Comparisons Tukey HSD

*) Tidak signifikan pada tingkat kesalahan 0,05

\section{Uji beda rerata faktor risiko resiliensi berdasarkan kota sekolah}

Pengambilan data pada kota Purwokerto dan Bojonegoro hanya pada tingkat pendidikan SMA. Dengan demikian pengujian hanya pada siswa SMA yang berada di kota Jakarta, Purwokerto dan Bojonegoro. Faktor risiko pemalakan dan informasi negatif terbukti ditanggapi dengan sikap sama bagi siswa SMA di Jakarta, Purwokerto dan Bojonegoro (sig.>0,05). Namun sebaliknya, faktor risiko Narkoba ditanggapi dengan sikap berbeda bagi siswa SMA di Jakarta, Purwokerto dan Bojonegoro (sig. $<0,05$ ). Faktor risiko bencana alam dan kemacetan lalu lintas mempunyai sikap yang sama pada siswa SMA di Jakarta dan Bojonegoro. Sedangkan faktor risiko perilaku seks bebas dan bullying memperlihatkan kesamaan bersikap pada siswa SMA di Jakarta dan Purwokerto.

Tabel 4. Pengujian beda rerata pada Kota Sekolah

\begin{tabular}{|c|c|c|c|}
\hline Faktor Risiko & $\begin{array}{c}\text { Kota } \\
\text { Sekolah }\end{array}$ & Purwokerto & Bojonegoro \\
\hline \multirow[t]{2}{*}{ Bencana Alam/Banjir } & Jakarta & 0,003 & $\left.0,074^{*}\right)$ \\
\hline & Purwokerto & & 0,000 \\
\hline \multirow[t]{2}{*}{ Perilaku Seks Bebas } & Jakarta & $\left.0,166^{*}\right)$ & 0,000 \\
\hline & Purwokerto & & 0,000 \\
\hline \multirow[t]{2}{*}{ Narkoba } & Jakarta & 0,001 & 0,000 \\
\hline & Purwokerto & & 0,000 \\
\hline \multirow[t]{2}{*}{ Bullying } & Jakarta & $\left.0,135^{*}\right)$ & 0,037 \\
\hline & Purwokerto & & 0,001 \\
\hline \multirow[t]{2}{*}{ Kemacetan lalu lintas } & Jakarta & 0,000 & $\left.0,254^{*}\right)$ \\
\hline & Purwokerto & & 0,000 \\
\hline \multirow[t]{2}{*}{ Pemalakan } & Jakarta & $\left.0,463^{*}\right)$ & $\left.1,000^{*}\right)$ \\
\hline & Purwokerto & & $\left.0,662^{*}\right)$ \\
\hline \multirow[t]{2}{*}{ Informasi Negatif } & Jakarta & $\left.1,000^{*}\right)$ & $\left.0,624^{*}\right)$ \\
\hline & Purwokerto & & $\left.0,652^{*}\right)$ \\
\hline
\end{tabular}

Pengujian menggunakan One-way ANOVA,Post Hoc Test, Multiple Comparisons Tukey HSD

*) Tidak signifikan pada tingkat kesalahan 0,05

\section{Pembahasan}

Pada penelitian ini populasi adalah remaja dengan usia sekitar 12 tahun dan 21 tahun. Kondidi ini terjadi karena adanya variansi berbeda dari sampel pada 7 faktor resiko. Oleh karena penggunaan populasi remaja perlu ditinjau kembali. Bila mengacu pada definisi usia remaja memang tidak ada yang sama. sama karena itu perlu ditinjau kembali mengenai populasi remaja 
menurut peneliti terdiri dari populasi berusia 12 tahun sampai dengan 15 tahun, populasi berusia 16 tahun sampai dengan 18 tahun dan populasi berusia 19 tahun sampai dengan 21 tahun. Dalam hal ini sesuai dengan teori perkembangan dikatakan masa remaja dimulai sekitar usia 10-12 tahun sampai 18-21 tahun (Santrock, 2005). Masa remaja adalah perubahan perkembangan dari usia sekitar 10 atau 11 tahun atau bahkan awal sampai akhir remaja atau awal usia 20 tahunan dan membutuhkan perubahan fisik, kognitif, dan psikososial. Menurut Hall, masa remaja dimulai dari usia 12-25 tahun, yaitu masa topan-badai atau strum und drang, yang mencerminkan kebudayaan modern yang penuh gejolak akibat pertentangan nilai-nilai (Rice \& Dolgin, 2008). Menurut E Erikson (dikutip dalam Steinberg, 2005), masa remaja adalah masa terjadinya krisis identitas atau pencarian identitas diri. Masa ini berada pada rentang usia 12-20 tahun.

Atas dasar usia populasi tersebut yang dapat diidentifikasikan sebagai usai SMP, usia SMA dan usia di semester 1 Perguruan Tinggi. Pada faktor-faktor risiko perilaku seks bebas, narkoba, pemalakan ditanggapi dengan sikap berbeda antara siswa SMP, SMA dan Politeknik. Tentunya, hal ini terkait dengan kematangan remaja. Menurut Papalia, Olds, dan Feldman (2007) remaja awal (sekitar usia 10, 11, atau 14 tahun) perubahan dari masa anak-anak, menuju kesempatan untuk berkembang, tidak hanya dalam ukuran fisik, tapi juga kemampuan kognitif dan sosial. Dengan kemampuan kematangan remaja akan mempengaruhi sikapnya terhadap faktor risiko resiliensi.

Terkait dengan budaya lokal terbukti bahwa remaja SMA di Jakarta, Purwokerto dan Bojonegoro berbeda sikap menyingkapi risiko yang dihadapinya. Perbedaan sikap tersebut mengenai narkoba. Namun mempunyai kesamaan sikap ketika dihadapi oleh situasi pemalakan dan mendapatkan informasi negatif dari sosial media. Remaja Jakarta mempunyai banyak sikap berbeda dengan remaja di Purwokerto dan Bojonegoro. Jika kita kaitkan dengan budaya lokal, tentunya remaja Jakarta memang mempunyai budaya lokal berbeda dari budaya lokal di Purwokerto dan Bojonegoro.

\section{KESIMPULAN DAN SARAN}

\section{Kesimpulan}

Hasil pengujian dengan menggunakan perbedaan rerata terbukti terdapat perbedaan sikap remaja dalam mengatasi 7 faktor risiko resiliensi. Berdasarkan tingkat pendidikan SMP, SMA dan Politeknik didapat hal yang sama yaitu terbukti terdapat perbedaan sikap remaja dalam mengatasi 7 faktor risiko resiliensi. Begitu pula berdasarkan kota lokasi SMA diperoleh bukti yang sama bahwa terdapat remaja SMA di kota berbeda terbukti memiliki sikap berbeda-beda terhadap 7 faktor risiko resilensi. Dengan demikian dapat disimpulkan bahwa 7 faktor risiko resiliensi ditanggapi dengan sikap berbeda oleh remaja berdasarkan pendidikan dan lokasi sekolah.

\section{Saran}

Penggunaan sampel penelitian sebaiknya dipisahkan antara sampel yang berasal dari populasi siswa SMP, populasi siswa SMA dan populasi siswa Perguruan Tinggi. Dalam hal menangani remaja usia remaja disarankan dilakukan penanganan berdasarkan tingkat pendidikan. Jika dicampur menjadi satu antara siswa SMP, SMA dan mahasiswa menjadi tidak efektif karena sikap dalam menangani permasalahan yang dihadapi berbeda. Pada penelitian ini budaya lokal setempat mempengaruhi sikap remaja hanya pada siswa SMA, sebaiknya dibuktikan juga terhadap siswa SMA dan mahasiswa. 


\section{Ucapan Terima Kasih (Acknowledgement)}

Terima kasih kepada siswa siswi dan mahasiswa yang berpartisipasi dalam penlitian ini. juga terima kasih kepada Lembaga Penelitian dan Pengabdian pada Masyarakat Universitas Tarumanegara yang telah memberikan fasilitas pada tim peneliti.

\section{REFERENSI}

Dewi, F.I.R. \& Mar'at, S. (2016) Adolescent resiliency of chinese benteng community: indigenous perspective. Proceeding Maranatha International Conference on Language, Literature \& Culture. Bandung, ISBN: 978-602-60681-0. 1.

Glicken, M. D. (2006). Learning from resilient people. America: Sage Publication

Grotberg, E. (1995). A guide to promotion resilience in children. Den Hag: Bernard Van Leer Fondation.

Grotberg, E. (1999). Tapping your inner strength. Oakland: New Harbinger Publication.

Kim, Y.C (1973) Oriental thought: An introduction to the philosophical and religious thought of asia. Illinois: Springfield. Charles C.Thomas Publisher.

Kim, U., Yang, K, \& Hwang, K. (2006). Indigenous and cultural psychology: Understanding People in context. New York, NY: Springer

Santrock, J. W. (2003). Adolescence (10 ${ }^{\text {th }}$ ed). New York: McGraw-Hill.

Schoon, I. (2006). Risk and resilience: adaptation in changing time. Cambridge: Cambridge University.

Steinberg, L.D (2005). Adolescence. McGraw-Hill Higher Education

Ungar, M. (2011). The social ecology of resilience: A handbook of theory and practice. The Springer. 